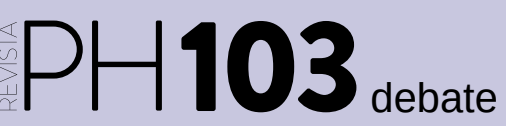

a debate Dilemas del arte urbano como patrimonio

| coordinan Elena García Gayo y Laura Luque Rodrigo

\title{
Dilemas del arte urbano como patrimonio. Conclusiones
}

\author{
Elena García Gayo | Servicio de Patrimonio Cultural, Diputación Provincial de Ciudad Real \\ Laura Luque Rodrigo | Dpto. de Patrimonio Histórico, Universidad de Jaén
}

URL de la contribución <www.iaph.es/revistaph/index.php/revistaph/article/view/4951>

Probablemente el arte urbano tenga que tener dos lecturas diferentes para ser comprendido con sus múltiples aristas, igual que el grafiti: una dentro de la contracultura y otra desde la cultura oficial. El arte urbano como movimiento no evoluciona, sino que da pie a nuevos lenguajes artísticos, o al menos no lo hace viajando desde la ilegalidad de sus propuestas a los encargos, porque son interpretaciones conceptualmente diferentes, como comenta Paula Resta en su contribución a este debate. De hecho, puede interpretarse que la creación de ese mal llamado "arte urbano" institucionalizado, reflexiona Pablo Navarro, no es sino un intento de maquillar algo preexistente, del que surge el muralismo contemporáneo, con una pátina de fingida modernidad con la que es empleado política y comercialmente.

En este sentido, el espacio urbano es un lugar diverso y heterogéneo que da cabida a distintos tipos de expresiones artísticas que adquieren valores y funciones diferenciadas, como apuntan María José Romero-Ternero y Marta Gómez, y que, aunque su nomenclatura a veces se confunda tanto académica como popularmente, generan distintas vías de investigación, que desembocan necesariamente en diversas opciones en cuanto a sus posibilidades de conservación y categorización. El debate que se propone, sobre sus funciones y valores, es tan antiguo como la propia existencia del arte y casi del ser humano, y al mismo tiempo enlaza con muchas contradicciones marcadas por su reconocimiento.

\section{De la provocación al ornamento}

Antes del boom de los 90, el arte urbano tuvo sus primeras incursiones en el espacio público por una necesidad de expresión libre, provocada por la masiva salida de jóvenes con una formación artística a un mercado laboral sin posibilidades. Se unieron juventud con rebelión e inconformismo contra un sistema elitista del mercado del arte, donde el monopolio de museos y galerías no era accesible para todo el mundo. Se empezaron a usar los muros de los edificios callejeros como soportes donde poder mostrar las obras, sin filtros de calidad y visibilizando su frustración, sin limitaciones, como reconoce Patricia Alonso.

Esa ausencia crítica, esa provocación intelectual positiva que identifica las obras artísticas en el espacio público, es una carencia y constituye uno de los dilemas de los cambios de uso de las expresiones artísticas en la calle, que necesitan un comisariado selectivo para separar el polvo de la paja. Las obras de rápida ejecución que se encuentran de forma fortuita en un lugar cualquiera dan paso a una versión aseada y ordenada, a "espacios culturales" delimitados. La elección libre del espacio, del diálogo o la interpretación del contexto, que es ya de por sí una materia inspiradora, queda sustituida por la selección de la disponibilidad fortuita de muros; se puede hablar de ellos como soportes reivindicativos, en apoyo de causas diferentes y que pueden interesar a muchos colectivos a través de interpretaciones irónicas, reivindicativas, que intentan concienciar de una realidad polarizada por la política o la economía, tal y como menciona Beatriz Garrido con las obras de Banksy.

Cuando la piel tatuada de la ciudad deja de ser libre se convierte en una pátina cultural de embellecimiento ornamental. La ciudad se torna en museo y los artistas trasladan los temas mecánicamente de muro en muro. Comienza la profesionalización. El proceso creativo cambia y se vuelve a pintar para la eternidad, pero esta vez sin reconocimiento para los artistas porque es un arte cuyo estigma es una cualidad efímera que obliga a una falta de tutela. 


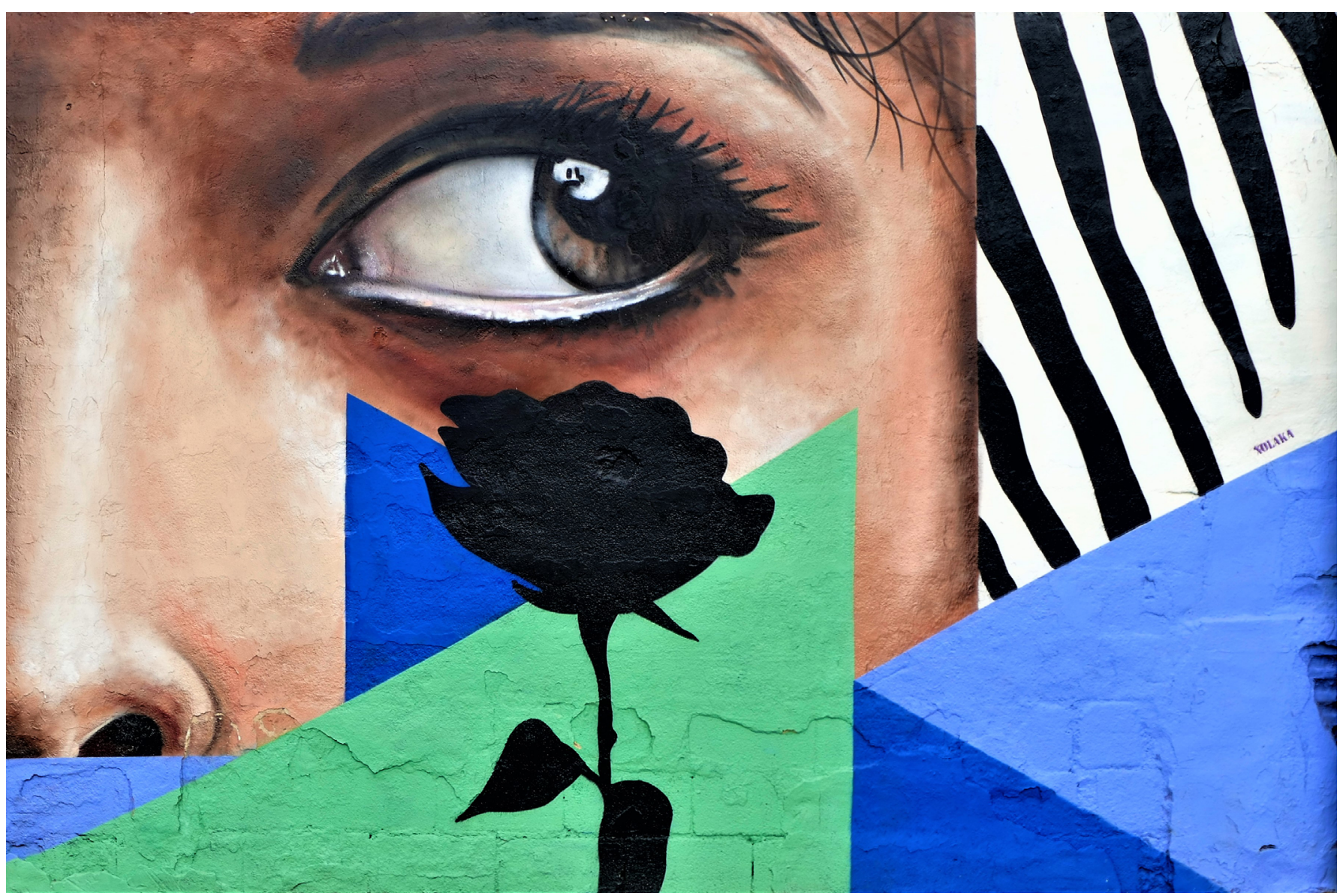

Arte urbano en Valencia | foto Antonio Marín Segovia

Los artistas 'urbanos', que son identificados por el contexto en el que se mueven, no tienen reconocimiento institucional, porque no dejan su cuaderno o un registro de su obra como rastro musealizable. Si llegan a las instituciones es por la vía tradicional. La experiencia urbana no se recibe directamente desde las obras urbanas, sino que es absorbida en un "total" documentado, cuando los protagonistas encuentran las vías ordinarias de acceso institucional.

La provocación de la calle no es fácilmente catalogable, aunque las obras sean de encargo. Quizá el caso PichiAvo de Valencia, descrito por Francisca Ramón Fernández, podría tener una lectura transversal en este aspecto.

\section{De hitos urbanos a monumentos sin pedestal}

Los lugares reconocibles en las ciudades son manifestaciones de artes vivas porque se identifican con su entorno. Comienzan como verdaderos hitos en los barrios. Es un patrimonio que surge desde abajo, desde grupos sociales y asociaciones, cuyos comisariados intentan revestir la superficie arquitectónica con una piel más humanizada.

La pregunta que se desprende de estas experiencias, encontradas, es si debe tener el arte una función. Cuestión ampliamente debatida y reflexionada desde la Antigüedad, que reaparece con el arte urbano, cuyo término, por moderno y actual, ya se promociona como un nuevo arte público. La realidad es que sus valores 
y funciones son múltiples y mutables a tenor del contexto en que se generan, del tipo de manifestación, del origen de la producción y de la relación que establezca con la comunidad en que se integra. Esos valores y funciones serán distintos según si se pregunta al artista, al viandante que lo contempla en su transitar diario, a un especialista en patrimonio o al alcalde de la localidad. Es importante desentrañar cuál de esos valores debe prevalecer e imponerse en cuanto a decidir los criterios sobre qué conservar y cómo, pues mantener alguna de las obras que se tornan en cotidianas es una de las claves de la patrimonialización, si bien debiera ser en base a criterios flexibles capaces de adaptarse a cada realidad contextual. Por otro lado, se demuestra absolutamente necesaria una investigación que propicie una genealogía de artistas y una crítica especializada de arte urbano y público que permita identificar de forma precisa cada tipología contenida en estas manifestaciones.

\section{De popular a patrimonio}

Es evidente que ya existe una patrimonialización, al menos de algunas obras de arte urbano, como se demuestra en la declaración BIC de una obra de EI Niño de las Pinturas, en Granada, entre otros ejemplos que han emergido en los textos que han conformado este debate (es el caso de Manuel Moragues, Darío Cobacho, Ana Fernández, Enric Font, Lorena López, M. Cristina Ferrer, Pau Aleixandre, Gerardo Jesús García, Gabriela Sánchez, Francisco Delgado y Francisco Javier Ostos).

La patrimonialización implica varias cuestiones que obligan a mantener alta la guardia. Por ejemplo, como señala Chema Segovia, el peligro de interpretar de forma artificiosa las producciones artísticas, lo que permite cuestionar si no será precisamente por este motivo por el que se haya producido tal institucionalización del muralismo en espacios públicos, puesto que al monumentalizar las obras se crea una interpretación oficial y otra oficiosa que arrebata la base reivindicativa, política, social y de libertad creativa que pudieran tener las obras autogestionadas, promoviendo algo que cada vez recibe más críticas, y es una ingente cantidad de pro- ducciones que no tienen unidad, que son productos de artistas paracaidistas que aterrizan sin conocer el contexto y que aceptan formar parte de un conjunto más o menos decorativo generando un vacío de contenido, como apunta Belén Díez. Bajo ese paraguas se recogen los 'comisariados' ejercidos a través de visitas guiadas, que enseñan las intervenciones más llamativas, las más recientes o las más conocidas en las redes sociales, en un intento popular de musealizar la calle y promover un turismo cultural. Todas las miradas se dirigen al muralismo para culpabilizarlo de procesos de gentrificación y mercantilización de un arte que nació al margen de la galería, del espacio museístico y del comercio artístico. Pero al mismo tiempo estas manifestaciones conviven con un arte urbano espontáneo o con el grafiti de firma que parece resurgir con fuerza en los últimos tiempos, quizá como efecto de respuesta, provocando así una tensión en la ciudad que no en pocas ocasiones se resuelve con el borrado de algún wall of fame para pintar (limpiar) el muro y embellecerlo con algún mural de encargo, bajo la lógica de la regeneración de los barrios. Ejemplos de esto son el caso de Tarragona que expone Darío Cobacho en el debate, el del Soho de Málaga, que nos cuenta María Andrés, donde se impuso la lógica neoliberal, y otros tantos menos conocidos, por ejemplo en Jaén, en la calle Muralla, ese wall of fame fue tapado con obras encargadas por la Universidad para una de las ediciones de la Noche en Blanco, provocando que algunos escritores pisaran parte de ellas, con el consiguiente rechazo de parte de la sociedad jiennense, que ni siquiera entendió la defensa del sucio grafiti por la existencia de un muro que antes era de acceso libre.

\section{De la degradación a la conservación}

Si lo contrario de la degradación es la conservación, entre medias existe un enorme mundo de posibilidades en el que la investigación en artes plásticas se convierte en objetivo fundamental para salvaguardar la memoria desde la documentación. Algunas de las opciones van a venir de la mano del artista, que a través de la técnica, los materiales o la localización -si la ha elegido él- marcarán una voluntad intrínseca de conservación preven- 


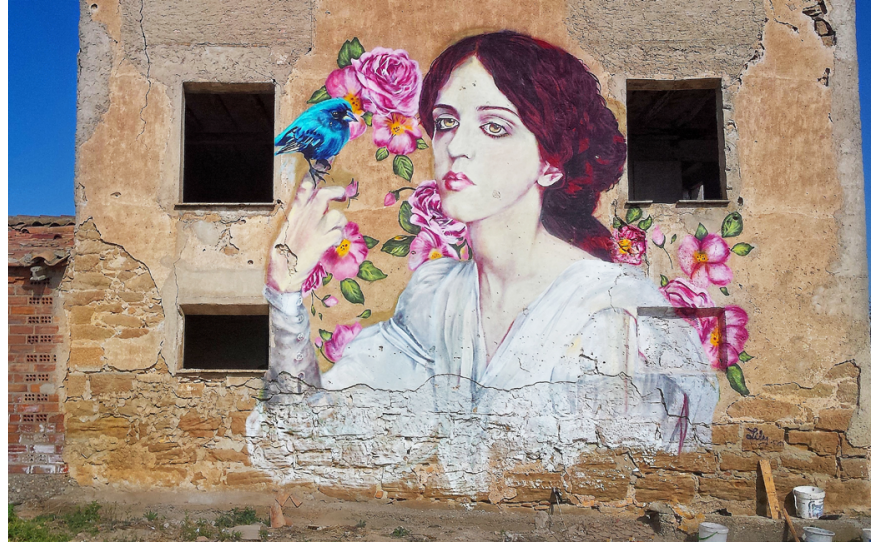

La dama de las flores, mural de Lily Brik ubicado en una torre del Cami de la Mariola en Lleida, 2016 | foto Manuel Portero

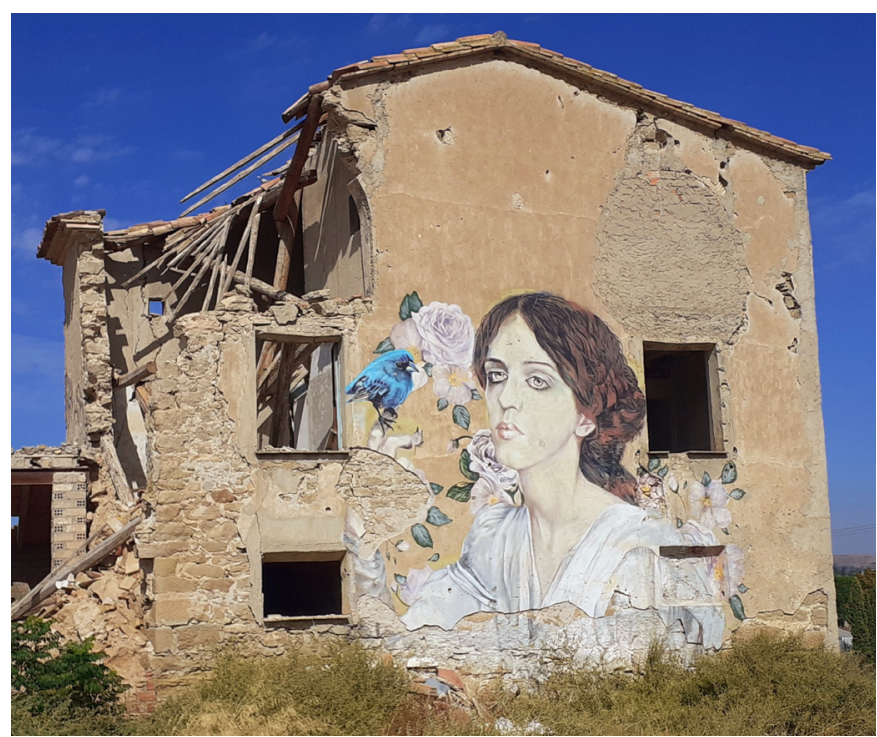

El mural en 2020 | foto AlbertRA

tiva que debe conocerse, de ahí la importancia de las entrevistas en la documentación de las obras de arte, que ofrecen información directa.

La patrimonialización no siempre implica la permanencia para la eternidad, y como el arte urbano es efímero, se puede llevar al extremo de respeto y simplemente alargar la vida material unos meses o unos años. Aunque queda por aclarar por qué la conservación aspira a la eternidad de forma sistematizada, cuál es su funda- mento, y sobre todo ayudaría a definir cuánto dura lo efímero: días, meses, años. Esto plantea numerosas dudas y una problemática sin solucionar sobre qué y cómo conservar. Si las obras deben sobrevivir tan solo a la generación que las creó, si se mantienen a través de cuidados paliativos, si podrían ir desapareciendo lentamente y dejar a la ciudad evolucionar sin lastres, o si la documentación, con todas sus posibilidades digitales, las sustituya; y, en esa dinámica, decidir sobre si la materialidad es una condición importante o si hay que centrarse en aspectos conceptuales.

En el sentido romántico de dejar morir las obras, parece existir consenso en el presente debate, en cuanto a no tutelarlas ni, en principio, intervenirlas con restauración, sino hacer que prevalezca el registro y documentación de las producciones, para lo que se hace necesario establecer un método de trabajo y de selección de piezas, pues es inviable catalogarlas en su totalidad, como afirma Mercedes Sánchez. Desde la consciencia de que realizar una selección implica un sesgo, los criterios deben ser versátiles y recoger todos los parámetros posibles, pues un arte producido por y para la ciudad debe ser respetado en su contexto, algo que implica el estudio de sus condicionantes y de su tiempo.

Aún así, se puede asegurar por algunos casos de sobra conocidos, como el de Muelle, mencionado por varios participantes, que la restauración de obras situadas en el espacio público es posible, siempre y cuando las iniciativas sean solicitadas y no impuestas. Respetadas sin usos partidistas. Sin cambios jurídicos, sin musealizar su espacio y en el lugar para el que fueron creadas. $Y$ esto es importante para que sean tan admiradas como respetadas. El reconocimiento de los artistas y el arraigo de las obras en su entorno es fundamental.

Siempre la materialidad contendrá información difícil de enlatar, y un seguimiento de su estado de conservación puede ayudar a ralentizar el envejecimiento. Una desaparición lenta y pautada pasaría la decisión de supervivencia a la siguiente generación de profesiona- 


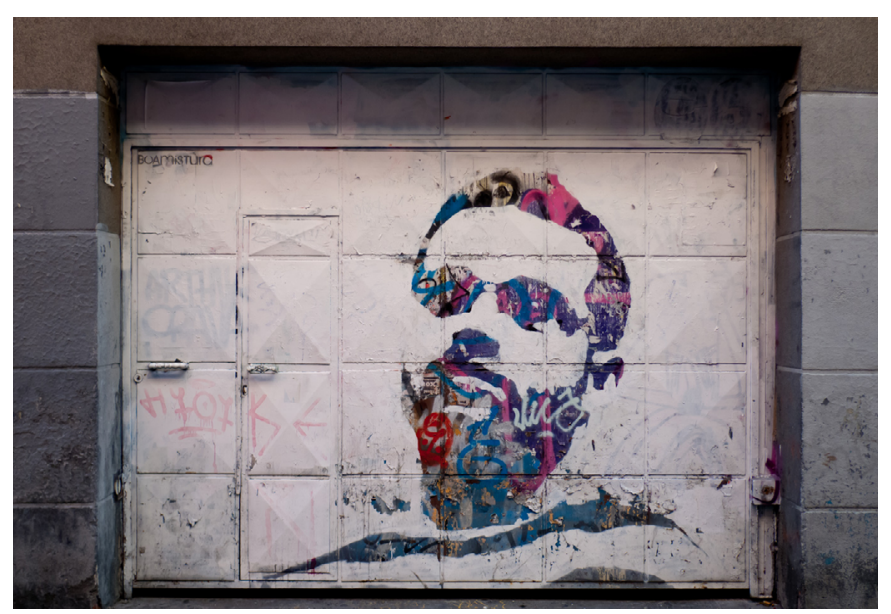

Boa Mistura | foto r2hox

les de patrimonio. Es posible que no exista una distancia suficiente en el tiempo para tomar decisiones en la actualidad, pero algo hay que hacer o no quedará nada.

La conservación de obras situadas en el espacio público requiere de una justificación que sólo puede partir del conocimiento de sus particularidades y del proceso creativo. Desde este punto de vista, cabe analizar minuciosamente desde la orientación del muro hasta el escaneo con drones o las más modernas técnicas de digitalización.

\section{De ilegal a regulada}

Para unos se hace necesario que este tipo de manifestaciones sean incorporadas a la normativa vigente; para muchos, como ya se ha indicado, deben permanecer al margen de la tutela legislativa; y para otros tantos, la manera de preservar algunas de estas manifestaciones pasaría por crear una figura híbrida entre lo material y lo inmaterial que priorice lo segundo. Esto genera la necesidad de crear un nuevo campo en la especialización patrimonial que sea capaz de generar archivos de memoria oral desde un punto de vista transdisciplinar. Además, se resalta la idea, ya expuesta por el Grupo de Arte Urbano y Público del GE-IIC en su Código Deontológico (García Gayo, Amor García, Luque Rodrigo et ál. 2016) y traida al debate por Stella Maldonado, de emplear la fórmula del BiComún para la protección de obras que implican

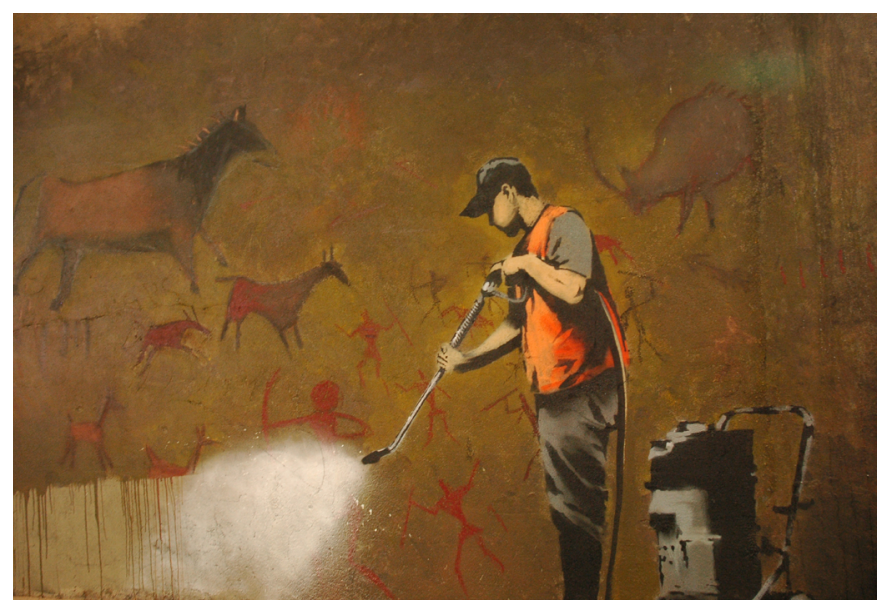

Cave Painting, Banksy | foto John Goodridge

la participación ciudadana y la conservación de aquellas que representan a colectivos concretos. En este sentido, se evidencia la capacidad, tanto del arte urbano como del arte público, de generar identidad sobre todo cuanto tiene que ver con el arte relacional y obras site specific (idea que apuntalan las contribuciones de Diego García y Nicolás Gallego). Además, como comentan Jennifer García y Manuel Moragues, en los últimos años el muralismo público (institucional) ha adquirido matices educativos, siendo frecuentes los programas relacionados con las escuelas, los valores sociales o con la puesta en valor de otros elementos patrimoniales que pueden llegar a reivindicar una faceta inmaterial. El objetivo es fomentar la identidaficación de los ciudadanos con el territorio y sobre todo en las pequeñas localidades rurales que padecen procesos de despoblación.

En lo que tiene que ver con obras ya existentes, si han sufrido un proceso de reconocimiento y se ha alterado alguno de los condicionantes fundamentales de su proceso creativo, las obras pueden llegar a cambiar su significado. Y si se transforman aspectos que tienen que ver con su situación jurídica sufrirá la misma vandalización pero esta vez institucional, lo que también alterará su significado. Se puede decir que la conservación tiene sus riesgos y debe estar justificada. Aspectos como el por qué, para qué y quién lo solicita, son importantes. 
La contribución de Eva Sòria en este debate nos recuerda que las obras situadas en el espacio público también están sujetas a derechos de autor, en los que se distinguen los derechos morales, en virtud de los cuales los autores conservarán una ascendencia legal sobre sus obras incluyendo, principalmente, el derecho de autoría y el de integridad, es decir, el derecho a impedir que un tercero modifique su obra sin su permiso. La calle se mueve dentro de unas reglas no escritas y parece que las instituciones a veces asumen como suya también esa particular regulación, de falta de respeto a la creatividad. Es importante preguntar si, tal y como propone Andrea Areddu, se asume el street art como instrumento de regeneración urbana, con reflejo en la política de las administraciones locales. Si se hace sin la complicidad de los artistas, ¿se estaría alterando su esencia?

\section{Del olvido a la catalogación}

Habrá que revisar significado y significante de las obras de arte situadas en el espacio urbano para las que se reivindica su carácter efímero por un condicionante de falta de titularidad y en aras del fácil abandono. Son obras que terminan convirtiéndose en virtuales, incluso antes de desaparecer, y se podría llegar a considerar un cierto carácter inmaterial, porque se desprecia su materialidad y contexto vital, con el que pasan a ser consumidas virtualmente, pero esto podría iniciar otro debate.

Volviendo a la catalogación, que emerge como la figura esencial en cuanto a la patrimonialización de arte urbano sin incidir en su condición de brevedad, el registro pasaría por incorporar -como no podría ser de otra manera- al artista como parte esencial y a través de las entrevistas profesionales, tal y como viene sugiriendo el Grupo de Arte Urbano y Público del GE-II (metodología que mencionan los textos de Rosa M. Gasol, Rosa Senserrich y Sergio Cruz). Asimismo se contempla la idea de conservar más la idea que la materialidad de la obra como dice Eva Sòria, lo que pasa no solo por la

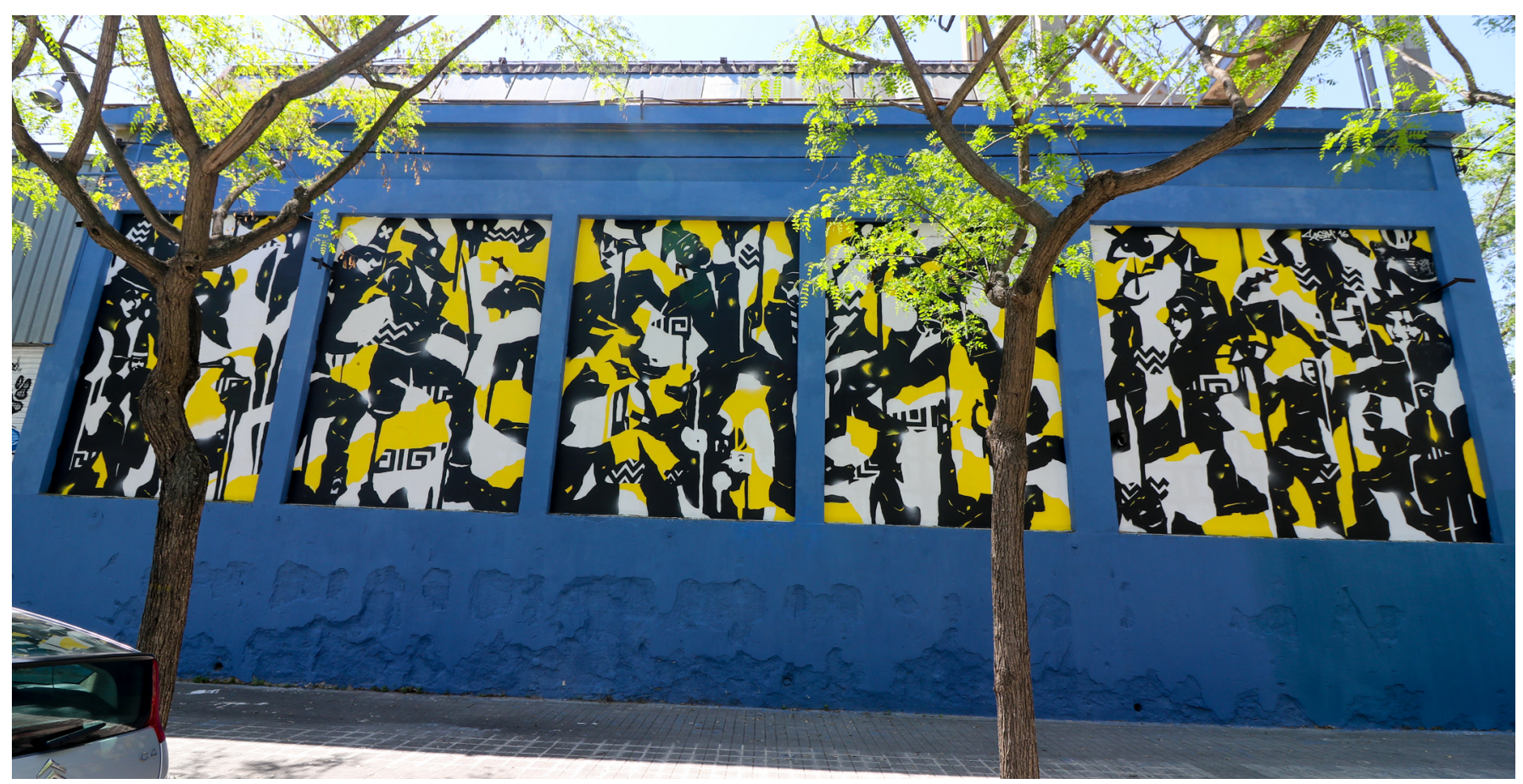

Mural de Maig en la Nau Bostik, La Sagrera (Barcelona) | foto Joan 


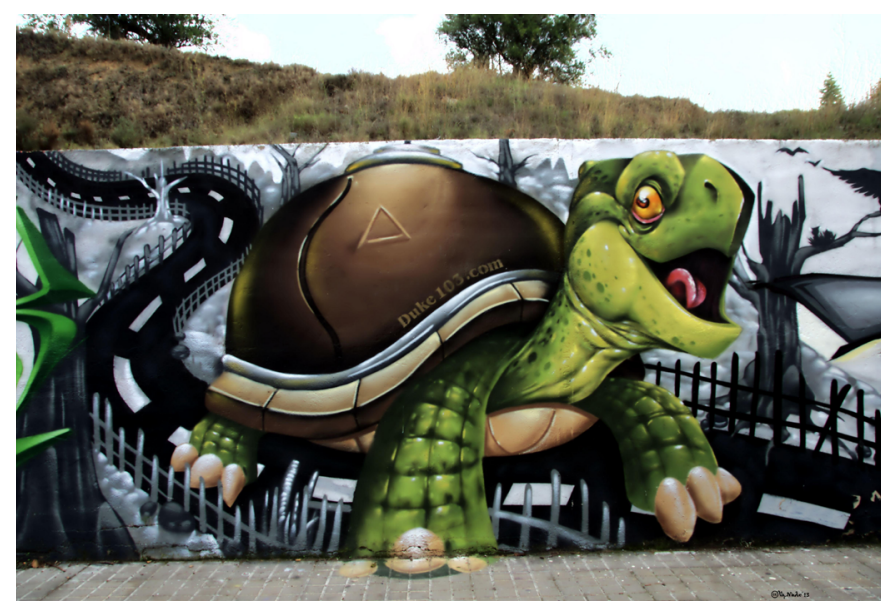

Mural del artista urbano Duke103 en Alcoy (Alicante) | foto Valentín Mejías

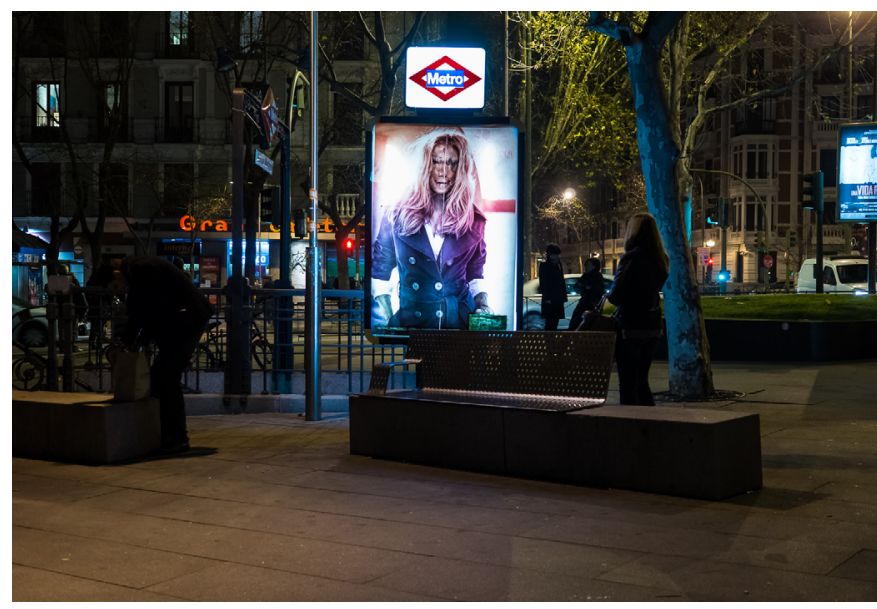

Disoluciones. Vermibus | foto r2hox

documentación sino que genera otros desafíos técnicos que suponen la incorporación de nuevos procesos en este campo. Además, la conservación material implica unos costes inviables para las instituciones, por lo que la virtual supone una alternativa y una fórmula de gestión viable y asequible. Una manera de respetar lo mutable de las manifestaciones artísticas en el espacio público, los cambios de parecer de los artistas y la obsolescencia del significado, pues no se puede desechar la idea de que la obra no esté terminada cuando el artista la deja, sino que el paso del tiempo, los agentes climáticos y la interacción con escritores espontáneos van conformando la obra, que termina integrándose en el paisaje, haciéndose testigo de cambios sociales hasta terminar por ser destruida y dar paso a otras nuevas, más apegadas a la realidad del momento.

Esto genera además la oportunidad de implementar esa estratigrafía urbana, propuesta en el debate por Víctor Almirón, empleando técnicas arqueológicas, una arqueología de paramentos que termina por ser más virtual que material siguiendo su etimología, la capacidad y necesidad de recordar, de mantener un testigo del pasado que perdure en la ciudad para recordar quiénes fuimos y qué decidimos, para seleccionar nuestro particular legado, el de nuestro tiempo, a generaciones futuras, porque convenimos en que necesitarán de esos hitos para mantener esa raigambre que nos une con las generaciones que nos precedieron.

\section{De material a virtual}

Con las posibilidades también llegaron los cambios. Los que afectan al soporte, a la experiencia estética, vivida y sentida con los cinco sentidos, y al contexto.

La intromisión de las redes sociales en el propio proceso creativo de las obras de arte urbano es absoluta. Los artistas ya no solo crean y suben ese producto a sus redes, sino que crean sus obras en función de cómo se verán en la foto (ideas apuntadas en los textos de Sandra Gracia y Carmen Haro). Las redes sociales nos generan ciertos beneficios. Por un lado, le dan al artista más visibilidad en cuanto al número de personas que conocerán su obra; y por otro, le da inmediatez, si bien a través de las redes sociales se pierde la comprensión total de la obra al quedar descontextualizada.

Este registro que hace el propio artista permitiría a la investigación tener una grandísima base de datos que documenta no sólo el resultado sino muchas veces incluso el proceso creativo, pero la realidad es que también la información es ingente y no es viable procesarla en su totalidad, por lo que finalmente continuaríamos haciendo ese cribado que puede ser tendencioso y sesgado. Por otro lado, la propia inmediatez de las redes genera que, de alguna forma, esos registros sean aún 


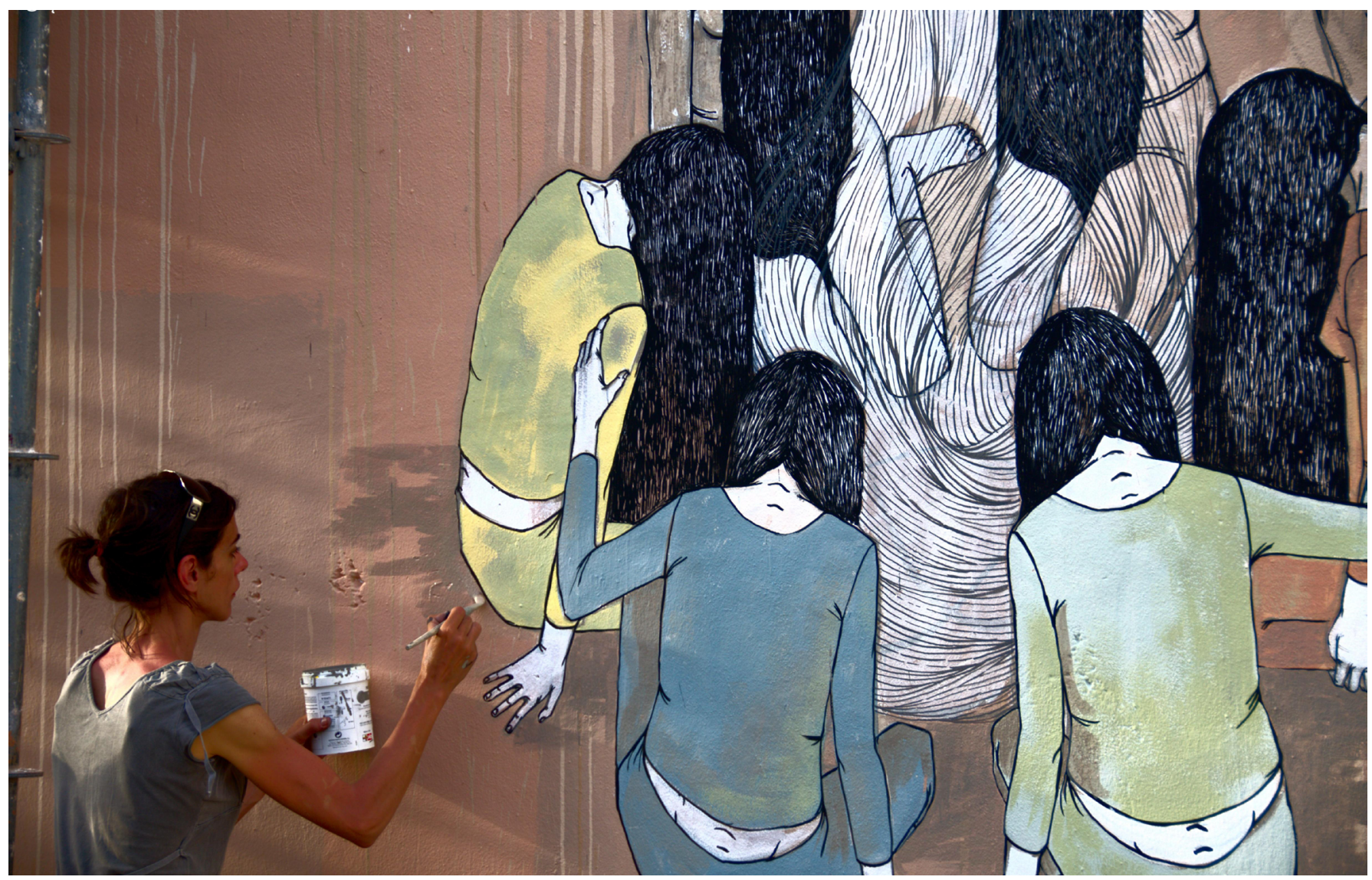

Hyuro en Poliniza'11 | foto Valentín Mejías

más efímeros en redes que en las calles, pues las siguientes publicaciones van relegando al olvido las primeras. Sin embargo, el seguimiento de las redes nos abre una vía de estudio interesante, mucho más compleja a pie de calle, como es conocer la opinión de los espectadores y poder registrarla, si bien posiblemente sean efectivamente meros espectadores de una fotografía, desconocedores del contexto, y al final son estas personas, las que conviven con las obras, quienes tienen las claves que dan significación a las mismas.

En última instancia, Internet se ha convertido incluso en una vía de creación, como ilustra Vermibus en su texto, a través de los NFT que abren una nueva línea de actuación. ¿Se podrán considerar estas obras dentro del cajón de sastre de lo público? En los museos de titularidad pri- vada ya están. Al fin y al cabo las redes sociales son una nueva categoría de lo público, entendido como de todos y para todos, hasta el punto de que las calles se han convertido en no lugares, transitados pero no vividos, espacios donde cada vez menos no se produce un efecto de socialización, pues esta se ha trasladado a lo virtual.

\section{Conclusiones}

A pesar de los dilemas expuestos, no se debe olvidar que la idiosincrasia del arte urbano y del muralismo contemporáneo es diversa, por lo que quizás en cuanto a las obras realizadas por encargo en los festivales, cada vez más prolíficos en el mundo, se profesionalicen progresivamente y se cuente entre los comisariados especialistas en patrimonio que ayuden a organizar la información necesaria. 
A medida que se construye la ciudad, se depositan significados y fórmulas de vida. Simultáneamente, el paisaje urbano actúa como un potente transmisor de activación de los sentidos que moldean el modo en que se percibe la realidad en la que nos proyectamos a nosotros mismos, como reconoce Chema Segovia.

Ese poso, después de más de cincuenta años de grafiti, gozando de una salud renovada, de treinta años de arte urbano, y de una cantidad creciente de propuestas transformadoras -incluidas las institucionales-, es evidente que no se puede hablar de tendencias artísticas efímeras, aunque sus producciones sí lo sean, y se vuelve necesario tomar una decisión de cara a la documentación ordenada de las propuestas, antes de que desaparezcan totalmente los inicios de una manifestación surgida del asalto artístico de la calle. En ese caso, también serán necesarias técnicas novedosas que permitan la conservación de algunos muros, al menos unos años, tanto si han sido preparados para ello previamente como si no, como apuntan las contribuciones de Carmen Moral, Iñaki Navarro y Andrea Fernández, porque lo importante es cómo se enfrenta el individuo a un trabajo de interpretación de un entorno tan cambiante como agresivo, cuál es su aportación y si va a terminar por recibirse como regalo creativo entre individuos.

En la búsqueda del tercer paisaje que describe Sandra Gracia en su texto, continúa la auténtica vía de creación urbana a la que tenemos que mirar, liberando al arte urbano de añadidos como puedan ser sus homólogos encargados o digitales o, tal vez, esta amalgama de producciones se relacionen de tal manera entre sí que obliguen a crear modelos de catalogación, gestión y conservación, independientes de las nuevas propuestas que se sucederán cada vez más rápido en el tiempo, tomando de las anteriores aquello que les interesa, desechando lo que ya no sirve, y volviendo a ello de nuevo cuando sea necesario.

\section{BIBLIOGRAFÍA}

- Abarca Sanchís, F.J. y García Gayo, E. (2013) Muelle, patrimonio cultural. En: Diego Barrado, L. y Lorente Lorente J.P. (coord.) Arte en las ciudades, las ciudades en el arte. Zaragoza: Universidad de San Jorge, pp. 153-163

- Amor García, R. (2019) Galerías, casas de subasta y Urban Art: evolución y paralelismos en las prácticas de arte independiente. Ge-conservación, vol. 16, pp. 125-133. Disponible en: https://ge-iic.com/ojs/index.php/revista/article/ view/701 [Consulta: 02/02/2021]

- Coluccio, C.E. (2019) "Viral Mural", entre el muralismo y los espacios virtuales. Ge-conservación, vol. 16, pp. 145-153. Disponible en: https://ge-iic.com/ojs/index.php/revista/article/ view/703 [Consulta: 02/02/2021]

- Dávila, R. (2020) Dreucol se 'salta' la cuarentena. La opinión de Málaga, 19 de abril de 2020. Disponible en: https:// www.laopiniondemalaga.es/cultura-espectaculos/2020/04/19/ dreucol-salta-cuarentena-27574432.html [Consulta: 02/02/2021]

- Figueroa Saavedra, F. (2007) El graffiti en metálico: análisis sobre el graffiti y la circulación monetaria. Historia y comunicación social, vol. 12, pp. 23-44. Disponible en: https://revistas.ucm. es/index.php/HICS/article/view/HICS0707110023A/19019 [Consulta: 02/02/2021]

- Figueroa Saavedra, F. (2007) Estética popular y espacio urbano: el papel del graffiti, la gráfica y las intervenciones de calle en la configuración de la personalidad del barrio. Revista de dialectología y tradiciones populares, tomo 62, cuaderno 1, pp. 111-144. Disponible en: http://dra.revistas.csic.es/index. php/dra/article/view/28/29 [Consulta: 02/02/2021]

- García Gayo, E. (2019) El espacio intermedio del arte urbano. Ge-conservación, vol. 16, pp. 154-165. Disponible en: https://ge-iic.com/ojs/index.php/revista/article/view/704 [Consulta: 02/02/2021]

- García Gayo, E. (2016) Etapas del Arte Urbano. Aportaciones para un protocolo de conservación. Ge-conservación, vol. 10, pp. 97-108. Disponible en: https://www.ge-iic.com/ojs/index. php/revista/article/view/401 [Consulta: 02/02/2021]

- García Gayo, E., Amor García, R.L., Luque Rodrigo, L., Senserrich Espuñes, R., Gasol Fargas, R.M., Mata Delgado, A.L., Pastor Valls, M.T., Sánchez Pons, M., Santabárbara Morera, C., Úbeda García, M.I., Vázquez de la Fuente, M.M., Giner Cordero, E. (2016) Anexo I: Propuesta de código deontológico para la conservación y restauración de arte urbano. Ge-conservación, vol. 10, pp. 186-192. Disponible en: https://www.ge-iic.com/ojs/index.php/revista/article/view/419 [Consulta: 12/05/2021]

- García Gayo, E. (2019) Murales urbanos: una sucesión de capas perdurables y efímeras. 20. ${ }^{a}$ Jornada de conservación de arte contemporáneo. Museo Nacional Centro de Arte 
Rreina Sofía, Madrid. Disponible en: https://www.academia. edu/41611285/Murales_urbanos_una_sucesi\%C3\%B3n_ de capas de pintura perdurables_y_ef\%C3\%ADmeras [Consulta: $\overline{0} 4 / 0 \overline{2} / 2021]$

- Luque Rodrigo, L. y Moral Ruiz, C. (2021) El arte urbano como patrimonio inmaterial. Posibilidades para su protección y difusión. En: I Simposio anual de Patrimonio Natural y Cultural ICOMOS España. Valencia: Editorial Universitat Politècnica de València, pp. 57-64. Disponible en: https://riunet.upv.es/ handle/10251/160166 [Consulta: 02/02/2021]

- Luque Rodrigo, L. (2016) Arte relacional en la calle. Casos de conservación colectiva. Ge-conservación, vol. 10, pp. 117125. Disponible en: https://www.ge-iic.com/ojs/index.php/ revista/article/view/405 [Consulta: 02/02/2021]

- Martí, J.C. (2020) El arte más vivo entra en la Generalitat. Levante, el mercantil valenciano, 29 de octubre de 2020. Disponible en: https://www.levanteemv.com/cultura/2020/10/29/arte-vivo-entra-fondosgeneralitat-21972842.html [Consulta: 04/02/2021]

- Moral Ruiz, C. y Luque Rodrigo, L. (2021) Técnicas de investigación y catalogación del arte urbano desde la transdisciplinariedad: aplicaciones y retos de futuro. En: I Simposio anual de Patrimonio Natural y Cultural ICOMOS España. Valencia: Editorial Universitat Politècnica de València, pp. 73-81. Disponible en: https://riunet.upv.es/ handle/10251/160178 [Consulta: 02/02/2021]

- Henriques, F. (2012) Metodologias de Documentação e Análise Espacial em Conservação de Pintura. Tesis doctoral. Universidad Católica Portuguesa, Porto (Portugal). Disponible en: https://www.academia.edu/30510455/Metodologias_de_ Documenta\%C3\%A7\%C3\%A3o_e_An\%C3\%A1lise_Espacial_ em_Conserva\%C3\%A7\%C3\%A30_de_Pintura [Consulta: 04/02/2021]

- Henriques, F., Cardeira, L., Bailão, A., Candeias, A., Gonçalves, A., Vieira, E. y Batista Pereira, F.A. (2016) Processos de documentação 2D e 3D em obras académicas de Adriano de Sousa Lopes do acervo da FBAUL. En: III Colóquio Internacional: Coleções de Arte em Portugal e Brasil nos séculos XIX e XX. Diponible en: https://www. researchgate.net/publication/311714853_Processos_de_ documentacao 2D e 3D em Obras Academicas de Adriano_de_Sousa_Lopes_do_Acervo_dä_FBAUL [Consulta: 10/02/2021]

- Henriques, F., Cardeira, L., Bailão,A., Candeias, A., Gonçalves, A., Vieira, E. y Pereira, Batista, F.A. (2016) Mapeamentos com QGIS de uma colecção de pinturas de Adriano de Sousa Lopes do Acervo da Faculdade de Belas Artes da Universidade de Lisboa. En: $3 .^{\circ}$ Encontro de Utilizadores QGIS Portugal; Ordem dos Engenheiros, Porto. Disponible en: https://www. researchgate.net/publication/321949521_Mapeamentos com_QGIS_de_uma_coleccao_de_pinturas_de_Adriano_de_ Sousa_Lopes_do_acervo_da_Faculdade_de_Belas_Artes_da
Universidade de Lisboa [Consulta: 10/02/2021]

- Santabárbara Morera, C. (2016) La conservación del arte urbano. Dilemas éticos y profesionales. Ge-conservación, vol. 10, pp. 160-168. Disponible en: https://www.ge-iic.com/ojs/ index.php/revista/article/view/409 [Consulta: 02/02/2021]

- Senserrich Espuñes, R., Gasol Fargas, R.M. (2016) El papel del conservador-restaurador en el Arte Urbano comisionado: reflexiones a partir de los datos recogidos en la Open Walls Conference 2015 de Barcelona. Ge-conservación, vol. 10, pp. 109-116. Disponible en: https://www.ge-iic.com/ojs/index.php/ revista/article/view/403 [Consulta: 02/02/2021]

- Úbeda García, M.I. (2016) Propuesta de un modelo de registro para el análisis y documentación de obras de arte urbano. Ge-conservación, vol. 10, pp. 169-179. Disponible en: https://www.ge-iic.com/ojs/index.php/revista/article/view/410 [Consulta: 02/02/2021] 